\title{
Quantifying Fe-OC associations in sediment using dithionite in Flow- Through Reactors (FTR)
}

\section{SILVIA PLACITU}

Université Libre de Bruxelles

Presenting Author: silvia.placitu@ulb.be

Quantifying Fe-OC associations in sediment using
dithionite in Flow-Through Reactors (FTR)
S.PLACITU ${ }^{1}$, S. ARNDT ${ }^{1}$, S. BONNEVILLE
1 Biogéochimie et Modélisation du Système Terre, Département Géosciences, Environnement et Société, Université Libre de Bruxelles, 50 av. F. D. Roosevelt, 1050 Brussels, Belgium (silvia.placitu@ulb.be)

In sediments, the carbon and iron cycles are tightly interconnected. Organic molecules can adsorb onto Fe(III) oxyhydroxides surface but also co-precipitate with dissolved $\mathrm{Fe}$ forms to create organo-mineral associations (Fe-OM). These processes are believed to preserve $\mathrm{OM}$ from mineralization and participate to the burial of organic carbon in sediments. Globally, approximately $21.5 \pm 8.6 \%$ of total organic carbon in sediment is believed to be bound within Fe-OM according to the citratebicarbonate-dithionite (CBD) extraction [1]. However, this method has some limitations. Chief among those is the need to run a "blank" extraction to evaluate the innocuity of high ionic strength used in the CBD method on the stability of loosely bound OC in sediment. Here we propose to use Flow-Through Reactor [2] to quantify Fe-OM in sediment. With respect to the classical CBD extraction, this setup presents several advantages: (i) it allows to work at a much lower concentration of $\mathrm{Na}$ dithionite which limits the "salt-effect' on bound OC (ii) and it avoids the use of citrate as Fe(II)-ligand. As the FTR setup preserves very well the natural structure and the physicochemical condition of the sediments, it also permits to explore the fate of Fe-OM under changing environmental conditions. We will discuss the first results obtained with our new FTRdithionite method on Fe-OM from sediment collected in the Scheldt Estuary (Belgium).

[1] Lalonde K, Mucci A, Ouellet A, Gélinas Y. Preservation of organic matter in sediments promoted by iron. Nature. 2012 Mar 7;483(7388):198-200. doi: 10.1038/nature10855. PMID: 22398559.

[2] C. Pallud, C. Meile, A.M. Laverman, J. Abell, P. Van Cappellen (2007) The use of flow-through sediment reactors in biogeochemical kinetics: Methodology and examples of applications, Marine Chemistry, Volume 106, Issues 1-2, Pages 256-271, ISSN 0304-4203, https://doi.org/10.1016/j.marchem.2006.12.011. 